\title{
Hydrodynamics and Mass Transfer in a Modified Three-phase Airlift Loop Reactor
}

\author{
Liu Mengxi ${ }^{1}$, Lu Chunxi ${ }^{1}$, Shi Mingxian ${ }^{1},{\text { Ge } \text { Baoli }^{2} \text { and Huang Jie }}^{3}$ \\ (1. State Key Laboratory of Heavy Oil Processing, China University of Petroleum, Beijing 102249, China) \\ (2. Chemicals and Marketing Company, China National Petroleum Corporation, Beijing 100011, China) \\ (3. Refining and Marketing Company, China National Petroleum Corporation, Beijing 100011, China)
}

\begin{abstract}
A modified internal-loop airlift reactor (MIALR) with a continuous slurry phase was studied to investigate the local hydrodynamic characteristics, including gas holdup, bubble size, bubble rise velocity and local mass transfer properties. Based on the analysis of geometrical construction and fluid properties of gas and slurry, MIALR was divided into six flow regions. In these flow regions, the local hydrodynamic characteristics were investigated over a wide range of operating variables. Furthermore, a new method was developed to measure the dissolved oxygen concentration. The volumetric mass-transfer coefficient in six flow regions was also calculated for comparison.
\end{abstract}

Key words: Airlift loop reactor, hydrodynamics, mass transfer, fluidization, multiphase flow

\section{Introduction}

In order to meet the requirements of different industrial processes, many types of modified gas-liquid-solid hybrid reactors have emerged in recent years. As an integration of conventional single reactors, the hybrid reactor provides remarkable advantages over conventional single reactors, such as high gas-holdup, excellent heat transfer capacity, various flow modes, high interfacial mass transfer rate and low power consumption. In this study, a novel hybrid reactor was developed for hydrate formation, Fischer-Tropsch synthesis and methanol synthesis etc. This hybrid reactor mainly includes three parts: spray-impingement, perforated plate, and MIALR. This paper is mainly aimed at MIALR. Hydrodynamics and mass transfer between gas and liquid in MIALR were investigated.

The three-phase internal airlift loop reactor is mainly operated with the mode of batch operation of slurry (Carla and Jindrich, 1999; Chisti, 1989; Lo and Hwang, 2003; Lu and Hwang, 1995; Miyahara and Kawate, 1993). Such an operation mode cannot satisfactorily meet the demands of the processes, in which the solid product must be discharged with liquid continuously. Therefore, it is highly desirable to develop a novel internal airlift loop reactor with continuous operation mode of gas and slurry. In the present study, a novel MIALR with a continuous slurry phase was developed, and the hydrodynamic and mass transfer characteristics were also investigated.

Owing to the complexity of multi-phase flow and the limitation of measurement technology, few studies have investigated the local hydrodynamics and local mass transfer properties of the internal airlift loop reactor, although the lack of adequate data actually limit the optimization and commercialization of internal airlift loop reactor. This paper presents the local characteristics of hydrodynamics and mass transfer in MIALR.

\section{Experimental}

The schematic diagram of the experimental apparatus is shown in Fig. 1. The MIALR is made of plexiglas with an inner diameter (ID) of $284 \mathrm{~mm}$ and a height of $1,700 \mathrm{~mm}$. A draft tube, with an ID of 186 $\mathrm{mm}$ and a height of $1,000 \mathrm{~mm}$, is situated coaxially inside the MIALR, and the ratio of the cross-sectional area of the draft tube to that of the annulus is 0.85 . In order to feed and discharge slurry continuously, a 50 $\mathrm{mm}$ ID downcomer pipe is mounted coaxially inside the draft tube, and another $50 \mathrm{~mm}$ ID pipe is placed at the bottom of MIALR. The bottom of the MIALR is a conical section with a cone angle of $60^{\circ}$.

Water and air were used as the liquid and gas respectively in the experiments. The solid was high-density polyethylene (HDPE) particles, with a density and mean diameter of $881.6 \mathrm{~kg} \cdot \mathrm{m}^{-3}$ and 243 $\mu \mathrm{m}$, respectively. In order to be hydrophilic, the HDPE particles were pretreated with polyvinyl chloride. The superficial velocity of slurry, $U_{\mathrm{Lr}}$, and the superficial gas velocity, $U_{\mathrm{Gr}}$, varied from 0.03 to $0.05 \mathrm{~m} \cdot \mathrm{s}^{-1}$ and 0.006 to $0.19 \mathrm{~m} \cdot \mathrm{s}^{-1}$, respectively, based on the cross-sectional area of the draft tube. The solid loading was from $5 \%$ to $15 \%$ (by volume).

Local gas holdup and, local bubble size, and local bubble rise velocity were measured by using a 
mono-electrode resistance probe and a dual-electrode resistance probe, respectively. More details about the measuring method and data processing were described in literature (Lo and Hwang, 2003).

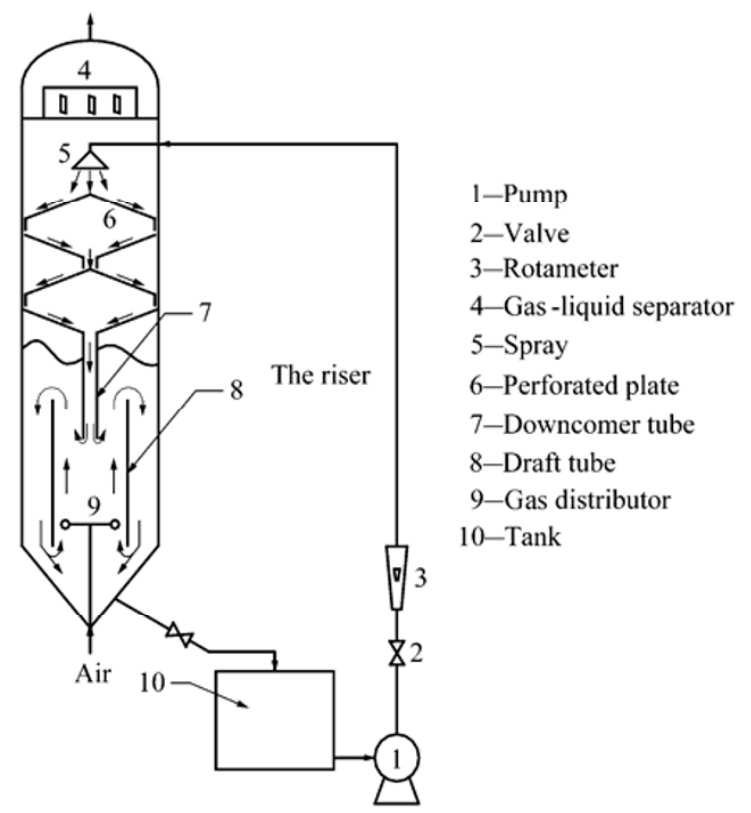

Fig. 1 Schematic diagram of experimental apparatus

A new steady-state method was developed to measure the dissolved oxygen concentration in the liquid. As shown in Fig. 1, the slurry was supersaturated with pure oxygen in a tank and then pumped into the hybrid reactor. When the supersaturated liquid contacted air in the hybrid reactor, the dissolved oxygen was transferred from liquid to air. In this method, the difference of the dissolved oxygen concentration between the inlet and the outlet liquid was as high as 14 $\mathrm{mg} / \mathrm{L}$, which greatly reduced the measurement error. The dissolved oxygen concentration was measured with a covered membrane galvanic oxygen sensor (WTW Model Cellox325) connected with an oxygen meter (WTW Model Oxi315i). In order to determine the saturation solubility of oxygen in water, liquid temperatures were also measured.

\section{Results and discussion}

\subsection{Local and overall gas holdup}

According to the transition of flow pattern and the complex geometrical structure, the MIALR was divided into six regions: gas distributor region, downcomer-affected region, draft tube region, gas-slurry separation region, bottom region and annulus region. Local gas holdup and local bubble size, and bubble rise velocity were measured at different radial locations and different regions. The six regions of MIALR are shown in Fig. 2.

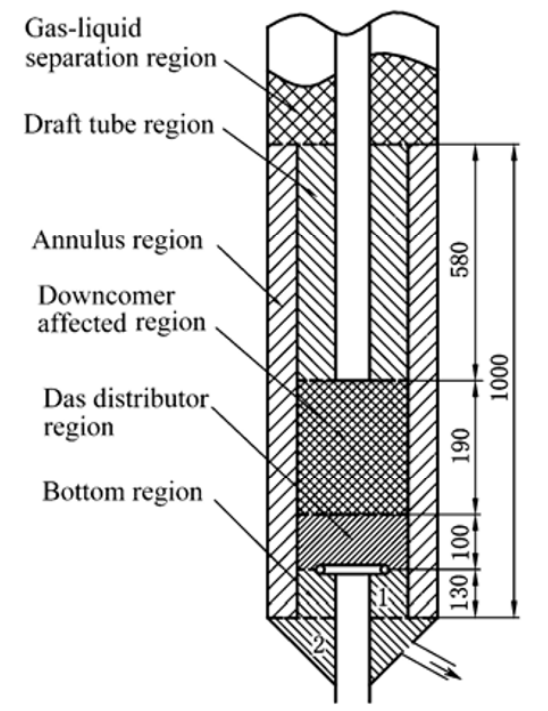

Fig. 2 Sketch diagram of flow regions of MIALR

The axial variation of the cross-sectional average gas holdup in the draft tube and in the annulus is shown in Figs. 3 and 4. In this study, the full bottom region consisted of two parts. Part 1 was the base conical zone and part 2 was the zone from the bottom of the draft tube to the top of the gas distributor (see Fig. 2). Experimental data indicated that there were almost no bubbles in the conical zone. Thus, the bottom region discussed here means just the zone from the base of the draft tube to the top of gas distributor. It was seen that the cross-sectional average gas holdup, $\bar{\varepsilon}$, was very small in the bottom region. This indicated that few circulation bubbles traveled from the annulus to the draft tube. Because the conical zone supplied a bigger flow space than the annulus, the fluids coming from the annulus, including slurry and bubbles, were sharply slowed down. Therefore, bubbles could not be carried into the draft tube except bubbles with very small diameter of internal airlift loop reactor. It is also shown in Fig. 3 that $\bar{\varepsilon}$ increased greatly in the gas distributor region and the downcomer-affected region. In the draft tube region, however, the variation of $\bar{\varepsilon}$ was very small. Fig. 4 shows that the axial evolution in the annulus was gradual and $\bar{\varepsilon}$ increased slowly with increasing axial height.

Fig. 5 shows the effect of superficial gas velocity $\left(U_{\mathrm{Gr}}\right)$ on overall gas holdup $\left(\bar{\varepsilon}_{\mathrm{MIALR}}\right)$, as a function of slurry velocity and solid loading. Overall gas holdup increased with increasing superficial gas velocity. Similar phenomena could be also observed in most internal airlift loop reactors (Blažej and Markoš, 2004; Contreras, et al., 1999; Lo and Hwang, 2003; Lu and Hwang, 1995). It is also seen in Fig. 5 (a) that slurry velocity has little effect on $\bar{\varepsilon}_{\text {MIALR }}$. 
But in Fig. 5(b), $\bar{\varepsilon}_{\text {MIALR }}$ increases with increasing solid loading.

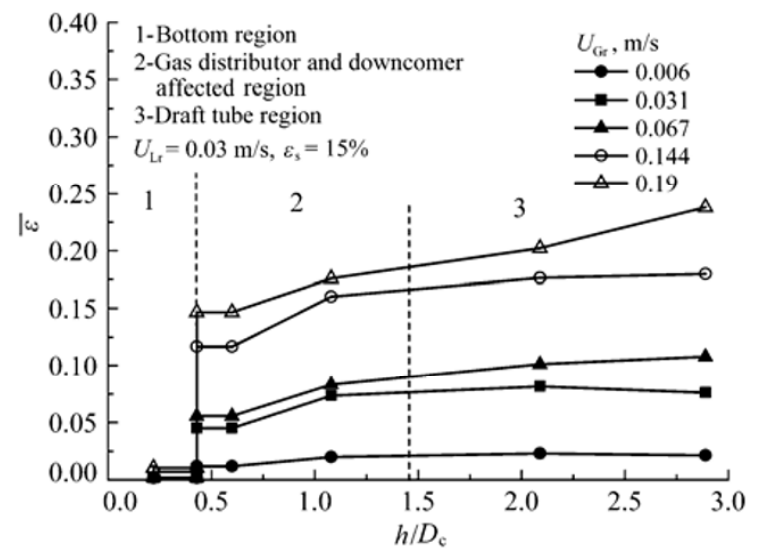

Fig. 3 Axial variation of cross-sectional average gas holdup in the draft tube

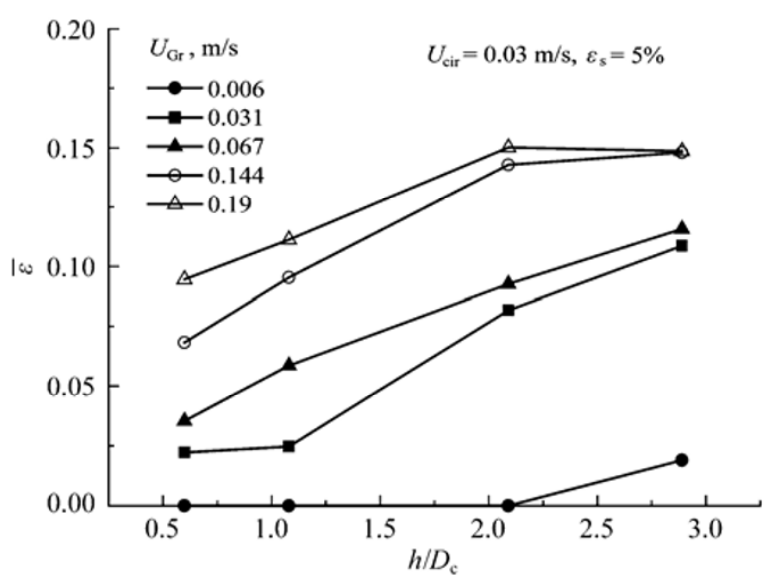

Fig. 4 Axial variation of cross-sectional average gas holdup in the annulus

\subsection{Local and overall bubble size}

Fig. 6 shows the axial variation of the crosssectional average bubble size $\left(d_{\mathrm{b}}\right)$ in the draft tube. Fig. 6 shows that when $h / D_{\mathrm{c}}<0.43$, corresponding to the bottom region, $d_{\mathrm{b}}$ was small. When $h / D_{\mathrm{c}}$ was in the range of $0.43-1.08$, corresponding to the gas distribution and downcomer-affected regions, $d_{\mathrm{b}}$ increased significantly with increasing axial height. In the draft tube region, when $h / D_{\mathrm{c}}$ was in the range of 1.08-2.90, the curve levels off. The axial variation of $d_{\mathrm{b}}$ in the annulus region is shown in Fig. 7. And Fig. 7 shows that the variation of $d_{\mathrm{b}}$ along the height of the annulus was relatively small, implying approximate equilibrium of coalescence and breakage of bubbles. Moreover, $d_{\mathrm{b}}$ in the annulus region was smaller than that observed in the draft tube.

Fig. 8 shows the effect of superficial gas velocity $\left(U_{\mathrm{Gr}}\right)$ on average bubble size $\left(d_{\mathrm{MIALR}}\right)$ in MIALR. Because feed slurry increased the circulation slurry

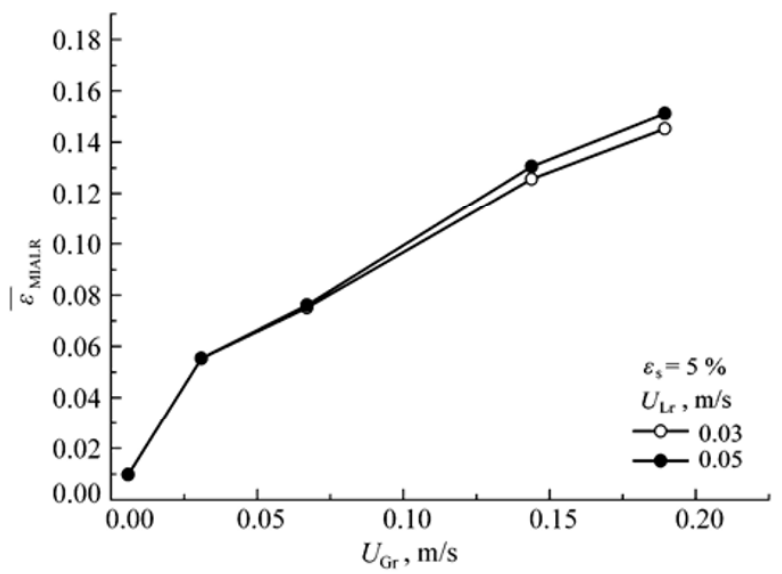

(a)

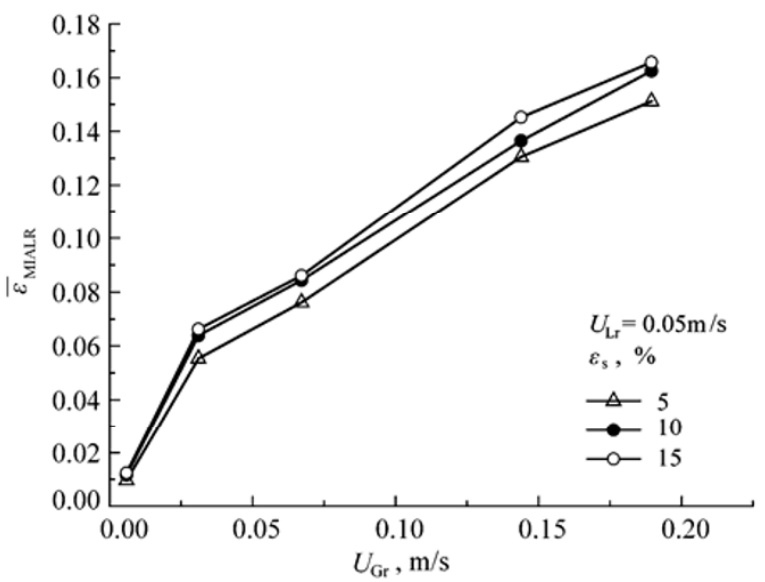

(b)

Fig. 5 Effect of $U_{\mathrm{Gr}}$ on $\bar{\varepsilon}_{\mathrm{MIALR}}$ as a function of $U_{\mathrm{Lr}}$ and $\varepsilon_{\mathrm{s}}$

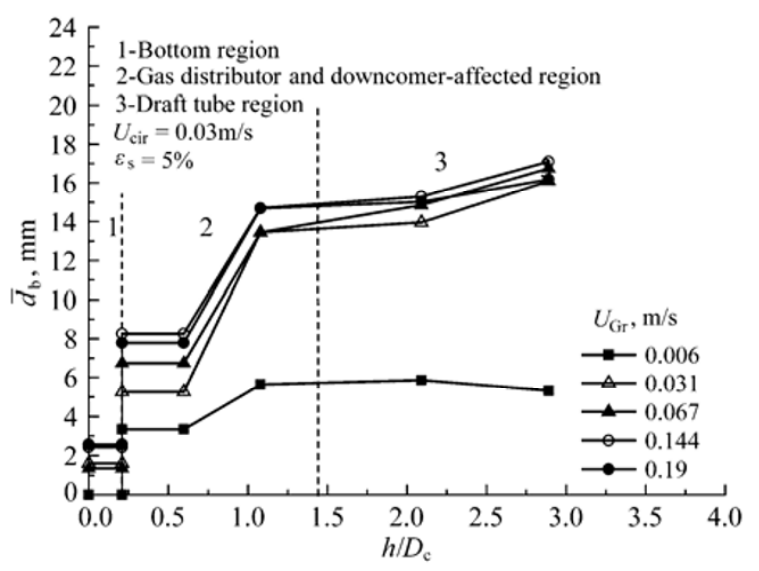

Fig. 6 Axial variation of cross-sectional average bubble size in the draft tube

velocity between draft tube and annulus and thereby enhanced the turbulence of slurry, $d_{\text {MIALR }}$ decreased with the increase of $U_{\mathrm{Lr}}$. Fig. 9 shows the effect of solid loading on average bubble size, and $d_{\text {MIALR }}$ decreased with increasing solid loading. Figs. 8 and 9 also show the effect of superficial gas velocity on $d_{\text {MIALR }}$, which increased significantly with increasing gas velocity. 


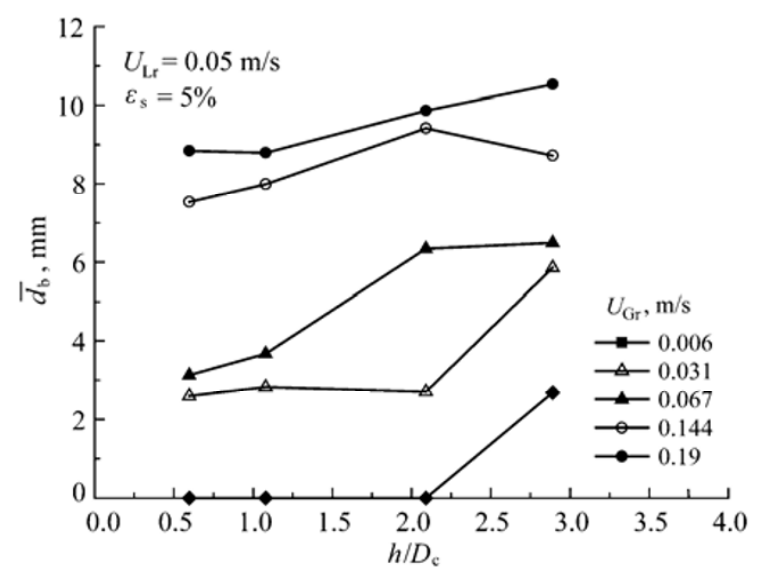

Fig. 7 Axial variation of cross-sectional average bubble size in the annulus

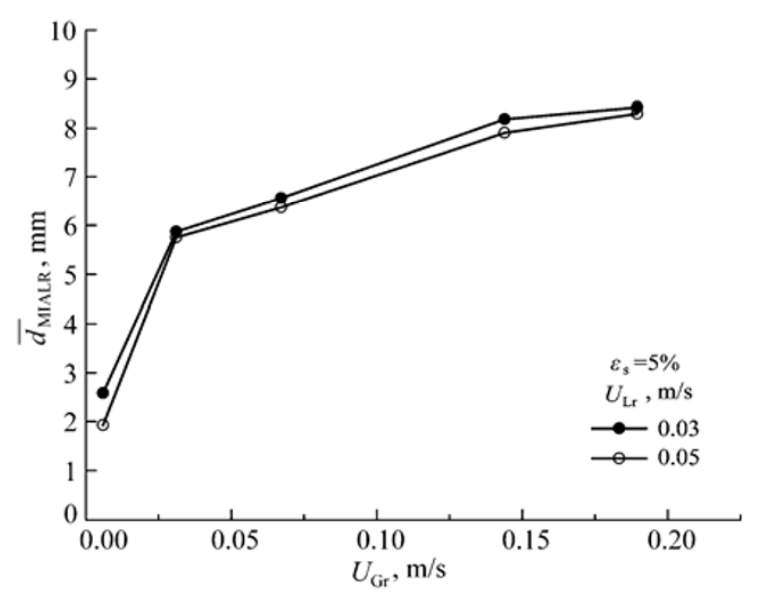

Fig. 8 Effect of superficial liquid velocity on average bubble size in MIALR

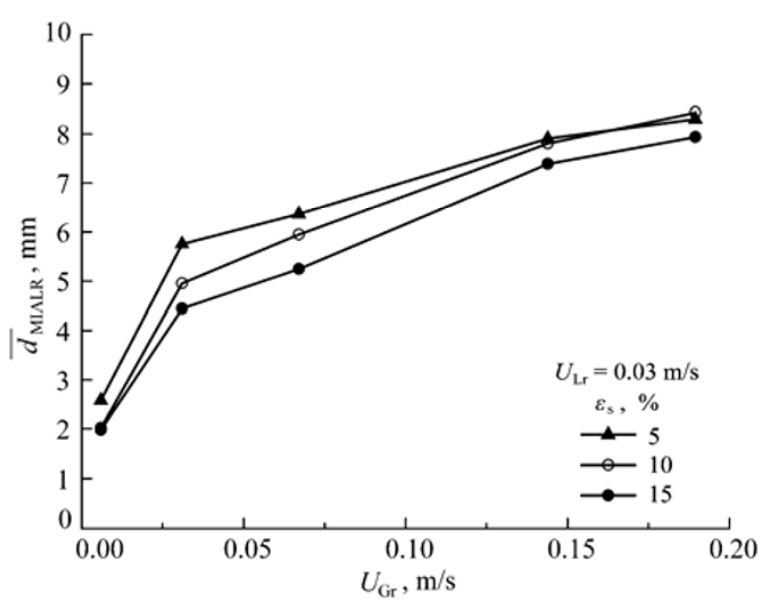

Fig. 9 Effect of solid loading on average bubble size in MIALR

\subsection{Bubble rise velocity}

The effects of superficial gas velocity, superficial slurry velocity and solid loading on bubble rise velocity in the draft tube region are shown in Figs. 10 and 11, respectively. They show that the bubble rise velocity increased with increasing superficial gas velocity. Fig. 10 also shows that bubble rise velocity decreased greatly with the increase of superficial slurry velocity. And Fig. 11 shows that bubble velocity also decreased as solid loading increasing.

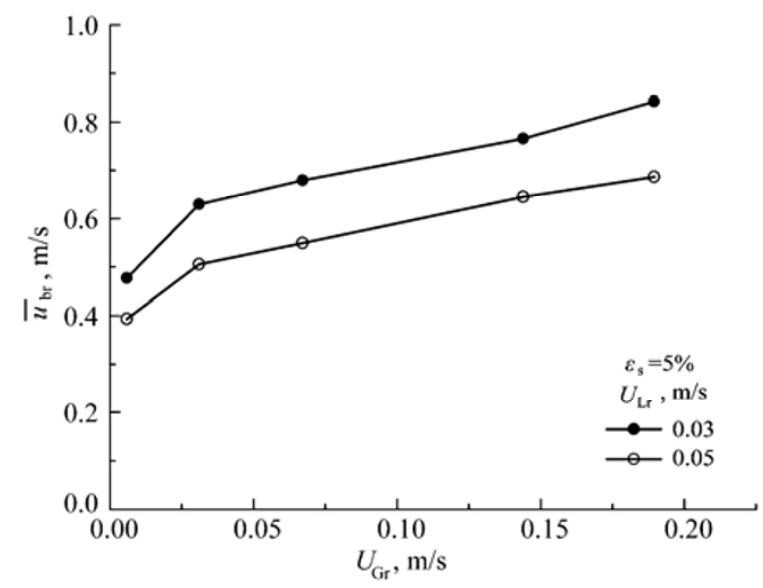

Fig. 10 Effect of superficial slurry velocity on bubble rise velocity in the draft tube

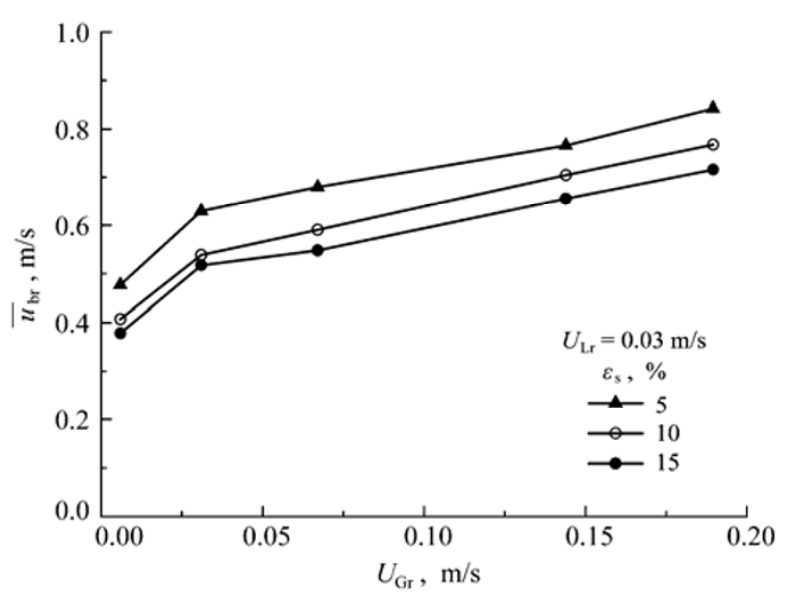

Fig. 11 Effect of solid loading on bubble rise velocity in the draft tube

\subsection{Local and overall volumetric gas-liquid mass transfer efficient}

The performance of gas-liquid mass transfer is an important factor for the design and scale-up of reactors. Numerous studies placed their focus on measuring and modeling of gas-liquid mass transfer characteristics. For gas-liquid-solid fluidized bed, many models, such as the backflow cell model (BFCM), the plug flow model (PFM) and the axial dispersion model (ADM), can be used to estimate the gas-liquid mass transfer coefficient $k_{\mathrm{L}} a$ by using the axial oxygen concentration distribution in liquid at static state. Although these models have been used in conventional gas-liquid-solid fluidization beds successfully, they might result in large 
errors in calculating $k_{\mathrm{L}} a$ for a more complicated fluidized bed with different flow modes. In internal airlift loop reactor, the flow modes in different regions are proved to be quite different (Merchuk, et al., 1992; $\mathrm{Li}$, et al., 1995), which results in different $k_{\mathrm{L}} a$ in different regions. Therefore, the ideal approach to investigating mass transfer behavior would be using different models for different flow regions. For the MIALR in the present study, the reactor was modeled by employing six ideal regions, namely gas distribution region, downcomer-affected region, draft tube region, gas-slurry separation region, annulus region and bottom region. More details about the six regions are shown in Fig. 2. The BFCM model was used for the gas distributor region, the downcomer-affected region and the gas-slurry separation region, whereas the ADM model was used for the draft tube region and the annulus region. Experimental data indicated only few bubbles in the bottom region, thus an assumption was made that there was no mass transfer in the bottom region.

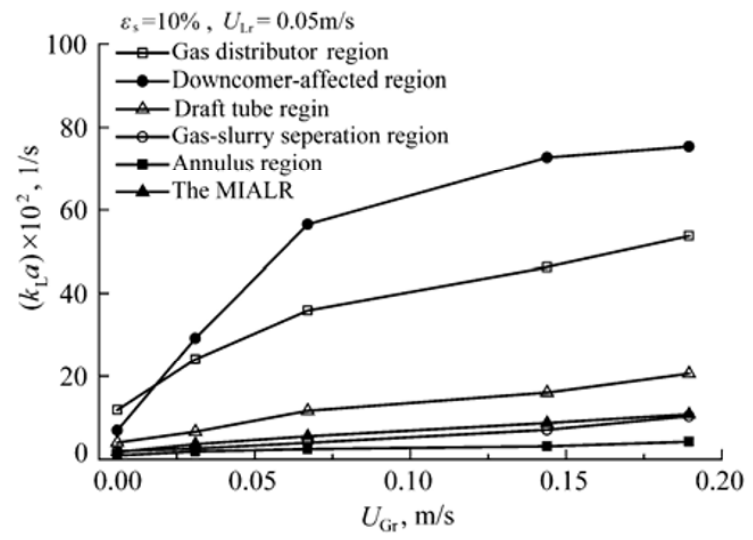

Fig. 12 Comparison of $\mathrm{k}_{\mathrm{L}} \mathrm{a}$ of different regions and the whole reactor

The gas-liquid mass transfer coefficient $k_{\mathrm{L}} a$ for different regions and the whole reactor is shown in Fig. 12. Comparison shows a substantial difference for $k_{\mathrm{L}} a$. $k_{\mathrm{L}} a$ was notably large for the gas distributor and downcomer affected regions, whereas it was very small for the annulus region. Particularly, the $k_{\mathrm{L}} a$ curve of the whole reactor is close to that of the gas-slurry separation region. These indicated that oxygen transferred from liquid to gas mainly occurred in the draft tube, thus, increasing the ratio of the cross-sectional area of the draft tube to that of the annulus might be helpful to enhancing the mass transfer capability of MIALR.

Figs. 13 and 14 show the effects of superficial gas velocity on $k_{\mathrm{L}} a$, as a function of superficial slurry velocity and solid loading, respectively. Figs. 13 and
14 show that $k_{\mathrm{L}} a$ increases with increasing superficial gas velocity. The cause might be that with the increase of gas velocity, the number of bubbles increases, and thereby $a$ is also increased. It is also seen that $k_{\mathrm{L}} a$ increases with the increase of superficial slurry velocity, while decreases with the increase of solid loading.

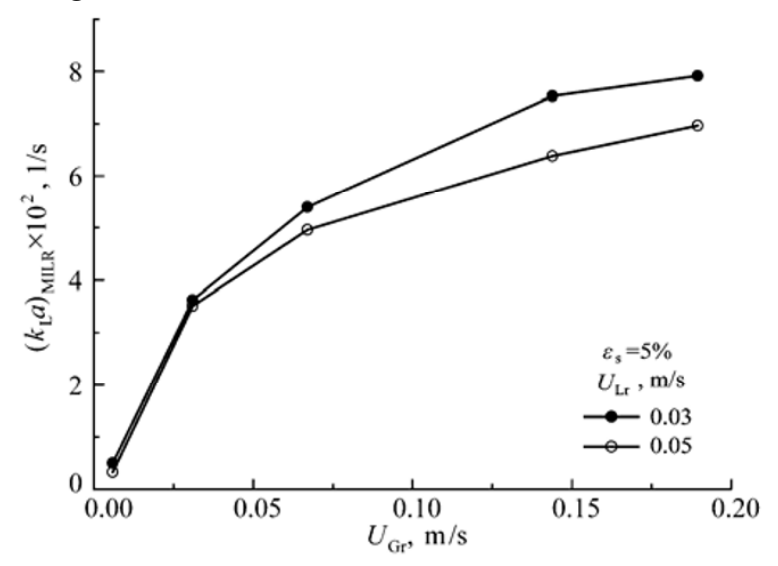

Fig. 13 Effect of superficial gas velocity on $\left(k_{\mathrm{L}} a\right)_{\text {MIALR }}$

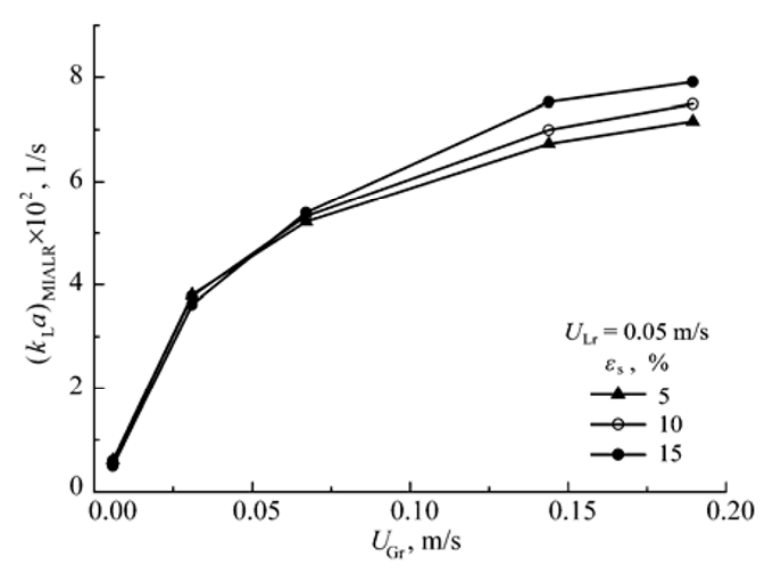

Fig. 14 Effect of superficial gas velocity on $\left(\mathrm{k}_{\mathrm{L}} \mathrm{a}\right)_{\text {MIALR }}$

\section{Conclusion}

Experiments were conducted to investigate the local hydrodynamic and gas-liquid mass transfer characteristics of a novel modified internal airlift loop reactor with a continuous slurry phase. It was found that the overall gas holdup increased with increasing superficial gas velocity, superficial slurry velocity and solid loading. Bubble size increased with increasing superficial gas velocity, but decreased with increasing superficial slurry velocity and solid loading. Compared with superficial gas velocity and solid loading, the effect of superficial slurry velocity on overall gas holdup and bubble size was small. Experimental results also showed that bubble rise velocity increased as superficial gas velocity increased, while it decreased as superficial slurry velocity and the 
solid loading increased.

A new method was developed to measure dissolved oxygen concentration in liquid. It was found that volumetric gas-liquid mass-transfer coefficient increased with increasing superficial velocities of gas and slurry, while it decreased slightly with increasing solid loading.

\section{Acknowledgements}

This work is financially supported by the National Basic Research Program of China (973 Program) (grant No. 2005CB221205), and by the National Natural Science Foundation of China (grant No. 20676147).

\section{Nomenclatures}

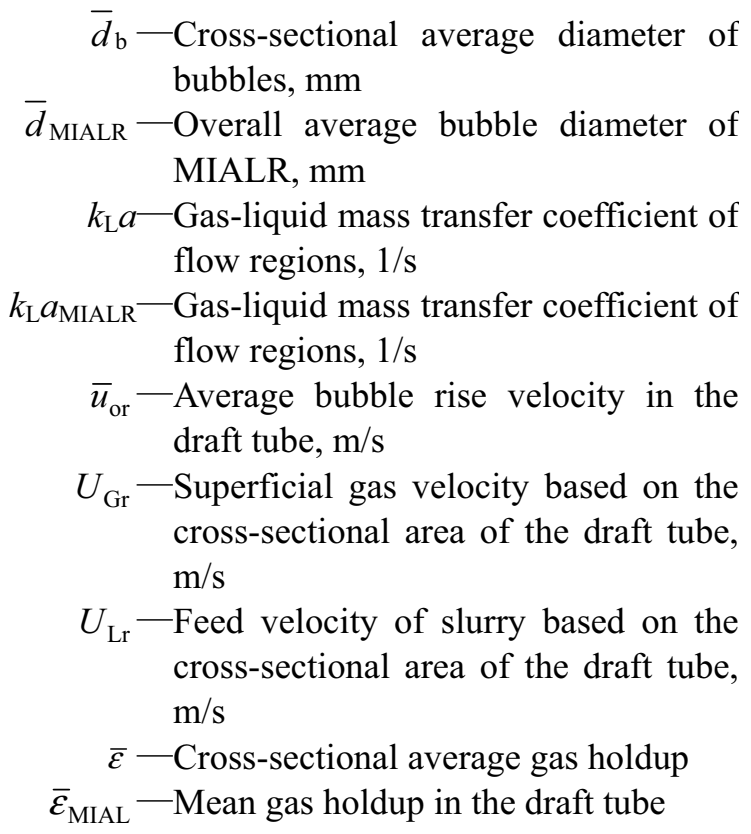

\section{References}

Blažej M. and Markoš J. (2004) Scale influence on the hydrodynamics of an internal loop airlift reactor. Chem. Eng.
Proc., 43, 1519-1527

Carla F. and Jindrich Z. (1999) Hydrodynamic model for three-phase internal- and external-loop airlift reactors. Chem. Eng. Sci., 54, 5253-5258

Chisti M. Y. (1989) Airlift Bioreactors. London: Elsevier Applied Science

Contreras A., García F., Molina E. and Merchuk J. C. (1999) Influence of spager on energy dissipation, shear rate, and mass transfer to sea water in a concentric-tube airlift bioreactor. Enzyme and Microbial Technology, 25, 820-830

Li G. Q., Yang S. Z., Cai Z. L. and Chen J. Y. (1995) Mass transfer and gas-liquid circulation in an airlift bioreactor with viscous non-Newtonian fluids. Chem. Eng. J., 56, B101-B107

Lo C. S. and Hwang S. J. (2003) Local hydrodynamic properties of gas phase in an internal-loop airlift reactor. Chem. Eng. J., 91, 3-22

Lu W. J. and Hwang S. J. (1995) Liquid velocity and gas holdup in three-phase internal loop airlift reactors with low-density particles. Chem. Eng. Sci., 50(8), 1301-1310

Merchuk J. C., Osemberg G., Siegel M., Sachem M. (1992) A method for evaluation of mass transfer coefficients in the different regions of air lift reactors. Chem. Eng. Sci., 47, 2221-2226

Miyahara T. and Kawate O. (1993) Hydrodynamics of a solid-suspended bubble column with a draft tube containing low-density particles. Chem. Eng. Sci., 48, 127-133

\section{About the first author}

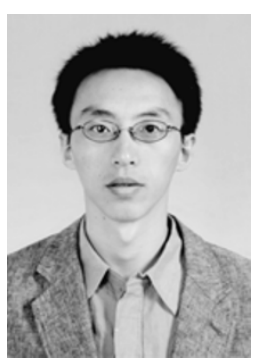

Liu Mengxi was born in 1973. He received his $\mathrm{PhD}$ degree from the China University of Petroleum (Beijing) in 2005. Now he works at the School of Chemical Science and Engineering in the China University of Petroleum (Beijing), with his research interests in fluidization and scale-up and commercialization of multiphase reactors. E-mail: mengxiliu@sina.com

(Received August 9, 2006) (Edited by Zhu Xiuqin) 